\title{
Liver Lipid Composition and Antioxidant Enzyme Activities of Spontaneously Hypertensive Rats after Ingestion of Dietary Fats (Fish, Olive and High-Oleic Sunflower Oils)
}

\author{
Valentina Ruiz-Gutiérrez, ${ }^{1}$ Carmen M. Vázquez, ${ }^{2}$ and Consuelo Santa-Maria ${ }^{3,4}$
}

Received April 3, 2001

Hypertension is associated with greater than normal lipoperoxidation and an imbalance in antioxidant status, suggesting that oxidative stress is important in the pathogenesis of this disease. Although many studies have examined the effect of antioxidants in the diet on hypertensión and other disorders, less attention has been given to the evaluation of the role of specific dietary lipids in modulating endogenous antioxidant enzyme status. Previously, we have described that liver antioxidant enzyme activities may be modulated by consumption of different oils in normotensive rats. The purpose of the present study was to examine the effects of feeding different lipidic diets (olive oil, OO, high-oleic-acid sunflower oil, HOSO, and fish oil, FO) on liver antioxidant enzyme activities of spontaneously hypertensive rats (SHR). Plasma and liver lipid composition was also studied. Total triacylglycerol concentration increases in plasma and liver of animals fed on the HOSO and OO diets and decreases in those fed on the FO diet, relative to rats fed the control diet. The animals fed on the oil-enriched diet show similar hepatic cholesterol and phospholipid contents, which are higher than the control group. Consumption of the FO diet results in a decrease in the total cholesterol and phospholipid concentration in plasma, compared with the high-oleic-acid diets. In liver, the FO group show higher levels of polyunsaturated fatty acids (PUFA) of the $(n-3)$ series, in relation to the animals fed on the diets enriched in oleic acid. Livers of FO-fed rats, compared with those of OO- and HOSO-fed rats showed: (i) significantly higher activities of catalase, glutathione peroxidase and $\mathrm{Cu} / \mathrm{Zn}$ superoxide dismutase; (ii) no differences in the NADPHcytochrome $c$ reductase activity. The HOSO diet had a similar effect on liver antioxidant enzyme activities as the $\mathrm{OO}$ diet. In conclusion, it appears that changes in the liver fatty acid composition due mainly to $n-3$ lipids may enhance the efficiency of the antioxidant defence system and may yield a benefit in the hypertension status. The two monounsaturated fatty acids oils studied (OO and HOSO), with the same high content of oleic acid, but different content of natural antioxidants, had similar effects on the antioxidant enzyme activities studied.

KEY WORDS: Detoxification enzymes; lipid composition; diet; liver; spontaneously hypertensive rats.

\section{INTRODUCTION}

Oxidative injury, due to free radicals, is associated with several diseases including essential hypertension [1]. The administration of antioxidants results in improved

\footnotetext{
${ }^{1}$ Instituto de la Grasa y sus Derivados (CSIC), Apartado 1078, Sevilla, Spain.

${ }^{2}$ Departamento Fisiología y Biología Animal, Facultad de Farmacia, c/Prof. García González s/n, 41012, Sevilla, Spain.

${ }^{3}$ Departamento de Bioquímica, Bromatología y Toxicología, Facultad de Farmacia, c/Prof. García González s/n, 41012, Sevilla, Spain.

${ }^{4}$ To whom correspondence should be addressed. Fax: +34 95 4233765; E-mail: csm@cica.es
} 
status in both hypertensive patients [2] and animal model [3]. Besides, it has become apparent that a variety of antihypertensive drugs have antioxidant activity, in addition to their primary function $[4,5]$. Probably, antioxidants reduce blood pressure via increasing availability of nitric oxide [2].

Dietary fat intake may also improve essential hypertension. It has been reported that consumption of polyunsaturated fatty acids (PUFA) lowers the blood pressure $[6,7]$. The antihypertensive effect of PUFA may be caused by changes in prostaglandin synthesis and also by alteration of membrane fatty acid composition, and subsequent changes in membrane functions [7]. The PUFA oils, as fish oil (FO), are very susceptible to peroxidation and production of free radicals.

Olive oil (OO), oil rich in monounsaturated fatty acids (MUFA), can also reduce blood pressure and promote cardiovascular health. Oleic acid is not necessarily the only component responsible for this effect and other antioxidant compounds contained in the non-glyceride fraction of $\mathrm{OO}$, such as sterols and polyphenols, may be additionally beneficial [8]. Although the traditional source of dietary MUFA is OO, other sources are now becoming available such as the new high-oleic-acid variety of sunflower oil (HOSO), which has a similar fatty acid composition but different antioxidant content [9]. It has been demonstrated that, unlike olive oil, the intake of HOSO does not provide favorable effects on hypertension related parameters [10]. The rate of peroxidation and production of free radicals, with the MUFA oils, is lower than that with the PUFA oils.

Previously, we have described that liver antioxidant enzyme activities may be modulated by consumption of different oils (OO, HOSO, and FO) in normotensive rats [11]. The antioxidant defence system in liver includes $\mathrm{Cu} / \mathrm{Zn}$ superoxide dismutase ( $\mathrm{Cu} / \mathrm{Zn}-\mathrm{SOD})$, catalase (CAT), and glutathione peroxidase (GSH-Px), enzymes that may be modulated by nutritional factors [12].

The aim of the present work was to compare the effects of dietary FO, OO, and HOSO on plasma and hepatic lipid composition and on some hepatic antioxidant enzyme activites in animals prone to cardiovascular disease, spontaneously hypertensive rats (SHR). The results show that the behavior of $\mathrm{CAT}, \mathrm{Cu} / \mathrm{Zn} \mathrm{SOD}$, and GSH-Px, seems to be related to the $n-3$ content of lipid in the liver. The FO diet provided the greatest antioxidant capability while the OO and HOSO diets, with the same high content of oleic acid, but different content of natural antioxidant, behaved similarly with regard to modulate the antioxidant enzyme activities in liver.

\section{MATERIALS AND METHODS}

\section{Animals and Diets}

Male SHR were obtained from IFFA CREDO (France). The animals weighed about $70 \mathrm{~g}$ at the beginning of the experiments and were housed in a well-ventilated room maintained at $22 \pm 2^{\circ} \mathrm{C}$ on a $12 \mathrm{hr}$ light-dark cycle. The rats were randomly divided into four groups of 10 animals. Each group was fed on one of the following diets for 12 weeks: a semipurified diet (basal diet) containing $2 \%$ by weight of unspecified lipid, purchased from Panlab SRL (Barcelona, Spain) (Control group) or the basal diet modified, supplemented with $10 \%$ by weight of olive oil (OO group) 
Table 1. Composition of Experimental Diets (g/Kg)

\begin{tabular}{|c|c|c|c|c|}
\hline Ingredient & Control & $\mathrm{OO}$ & HOSO & $\mathrm{FO}$ \\
\hline Casein & 209 & 203 & 203 & 203 \\
\hline Sucrose & 450 & 374 & 374 & 374 \\
\hline Cornstarch & 202 & 180 & 180 & 180 \\
\hline Lipids & 20 & 20 & 20 & 20 \\
\hline $\mathrm{OO}$ & - & 100 & - & - \\
\hline HOSO & - & - & 100 & - \\
\hline FO & - & - & - & 100 \\
\hline Cellulose powder & 52 & 56 & 56 & 56 \\
\hline Mineral Mix $^{a}$ & 57 & 57 & 57 & 57 \\
\hline Vitamin $\operatorname{mix}^{b}$ & 10 & 10 & 10 & 10 \\
\hline Total energy (MJ) & 15.2 & 17.1 & 17.1 & 17.1 \\
\hline Percentage proteins & 23.1 & 19.7 & 19.7 & 19.7 \\
\hline Percentage lipids & 4.9 & 26.3 & 26.3 & 26.3 \\
\hline Percentage carbohydrates & 71.9 & 53.9 & 53.9 & 53.9 \\
\hline
\end{tabular}

OO, olive oil; HOSO, high-oleic-acid sunflower oil; FO, fish oil.

${ }^{a}$ Mineral mix (mg/g): $\mathrm{NaCl} 139.3, \mathrm{~K}_{2} \mathrm{HPO}_{4}$ 389.1, $\mathrm{CaCo}_{3} 381.4$, $\mathrm{MgSO}_{4} .7 \mathrm{H}_{2} \mathrm{O} \quad 57.3, \quad \mathrm{FeSO}_{4} .7 \mathrm{HO}_{2} \quad 27.0, \quad \mathrm{MnSO}_{4} \cdot \mathrm{H}_{2} \mathrm{O}$ 4.0, $\mathrm{ZnSO}_{4} .7 \mathrm{HO}_{2} 1.25, \mathrm{Kl} 0.8, \mathrm{CuSO}_{4} .5 \mathrm{HO}_{2} 0.5, \mathrm{CoCl}_{2} .6 \mathrm{H}_{2} \mathrm{O} 0.02$.

${ }^{b}$ Vitamin mix (in Kg diet): vitamin A, $19800 \mathrm{Ul}$; vitamin D, $2500 \mathrm{Ul}$; vitamin $B_{1}, 20 \mathrm{mg}$; vitamin $B_{2}, 15 \mathrm{mg}$; vitamin $B_{3}, 70 \mathrm{mg}$; vitamin $B_{6}$, $10 \mathrm{mg}$; vitamin $\mathrm{B}_{7}, 150 \mathrm{mg}$; vitamin $\mathrm{B}_{12}, 50 \mathrm{mg}$; vitamin $\mathrm{E}, 170 \mathrm{mg}$; vitamin $\mathrm{K}$, $40 \mathrm{mg}$; choline, $1.36 \mathrm{~g}$; folic acid, $5 \mathrm{mg}$; p-aminobenzoic acid, $50 \mathrm{mg}$; biotin, $0.3 \mathrm{mg}$.

or high-oleic-acid sunflower oil (HOSO group) or fish oil (FO group). The composition of the experimental diets is shown in Table 1. To minimize oxidation, all diets were prepared once weekly and stored at $4^{\circ} \mathrm{C}$ under an atmosphere of nitrogen until needed. Changes in composition during storage were not detected.

The fatty acid compositions of the oils were determined and are shown in Table 2. The non-fatty acid components of the oils are presented in Table 3.

\section{Tissue Preparations}

At completion of the study the animals were killed by cervical dislocation. To minimize diurnal variations the rats were routinely killed between 09.00 and $10.00 \mathrm{hr}$. Blood samples were removed from the heart and collected into EDTA-containing $(1 \mathrm{~g} / 1)$ tubes. Plasma was separated by low-speed centrifugation at $1500 \mathrm{~g}$ at $4^{\circ} \mathrm{C}$ for 30 min and was immediately analyzed. Cholesterol, phospholipid, and triacylglycerols were determined with an autoanalyzer and conventional enzymatic methods [13-15].

The livers were immediately rinsed in ice-cold $0.145 \mathrm{M} \mathrm{NaCl}$, trimmed and quickly weighed. A $2 \mathrm{~g}$ portion of liver was used for lipid extraction and the rest was used to determine enzyme activities. All subsequent processing procedures were 
Table 2. Fatty Acid Composition (\%) of Dietary Fats

\begin{tabular}{lcccc}
\hline Fatty acids & Control & OO & HOSO & FO \\
\hline $14: 0$ & - & - & - & 3.8 \\
$16: 0$ & 13.2 & 11.8 & 4.3 & 13.9 \\
$16: 0(n-7)$ & 1.2 & 0.9 & 0.1 & 15.1 \\
$17: 0$ & - & 0.4 & 0.1 & - \\
$18: 0$ & 3.1 & 2.8 & 4.7 & 0.9 \\
$18: 1(n-9)$ & 36.8 & 79.2 & 80.2 & 26.2 \\
$18: 2(n-6)$ & 41.7 & 3.5 & 9.4 & 5.1 \\
$18: 3(n-3)$ & 4.1 & 0.6 & 0.1 & 0.2 \\
$18: 4(n-3)$ & - & - & - & 2.5 \\
$20: 0$ & - & 0.3 & 0.4 & - \\
$20: 1(n-9)$ & - & 0.2 & 0.2 & 2.4 \\
$20: 2(n-6)$ & - & - & - & 1.4 \\
$20: 3(n-6)$ & - & - & - & 0.4 \\
$20: 4(n-6)$ & - & - & - & 0.6 \\
$20: 5(n-3)$ & - & - & - & 13.8 \\
$22: 6(n-6)$ & - & - & - & 0.3 \\
$22: 6(n-3)$ & - & 0.4 & 0.4 & - \\
$24: 0$ & & - & & - \\
\hline OO olive oil; HOSO high-oleic-acid sunflower oil; FO, fish oil.
\end{tabular}

carried out at $0-4^{\circ} \mathrm{C}$. Homogenates $(10 \% \mathrm{w} / \mathrm{v})$ were prepared in $0.25 \mathrm{M}$ sucrose, $1 \mathrm{mM}$ EDTA, $1 \mathrm{mM}$ DL-dithiothreitol and $15 \mathrm{mM}$ Tris- $\mathrm{HCl}$ (pH 7.4), using an allglass Potter Elvehjem homogenizer. Each homogenate was centrifuged for $20 \mathrm{~min}$ at $800 \mathrm{~g}$. The resulting supernatant fraction was used to determine enzyme activities.

Table 3. Composition in Non-Fatty Acid Components of the Experimental Oils

\begin{tabular}{lccc}
\hline & OO & HOSO & FO \\
\hline Total unsaponifiable fraction (\%) & 1.5 & 1.0 & 1.1 \\
Total sterols (mg/Kg) & 1696 & 1754 & 1500 \\
Cholesterol (\%) & 0.15 & 0.01 & 100 \\
Brasicasterol (\%) & - & 0.32 & - \\
Campesterol (\%) & 3.80 & 10.25 & - \\
Stigmasterol (\%) & 0.81 & 11.59 & - \\
$\beta$-sitosterol (\%) & 93.99 & 59.35 & - \\
$\Delta$-5-avenasterol (\%) & - & 2.88 & - \\
$\Delta$-7-stigmasterol (\%) & 0.22 & 11.84 & - \\
$\Delta$-7-avenastero (\%) & 0.15 & 3.27 & - \\
Squalene (mg/Kg) & 3000 & 90 & 7400 \\
Tocopherols 9mg/Kg) & 47 & 10 & 300 \\
$\alpha$-tocopherols & 34 & 10 & 300 \\
$\gamma$-tocopherols & 13 & - & - \\
Fraction of polyphenols & 470 & - & - \\
Total polyphenols (mg/Kg) & 430 & - & - \\
Ortodiphenol (mg/Kg) & 40 & - & - \\
\hline
\end{tabular}

OO, olive oil; HOSO, high-oleic-acid sunflower oil; FO, fish oil. 


\section{Extraction and Separation of Lipids}

Quantitative extraction of total lipids from $2 \mathrm{~g}$ liver was carried out following the method of Folch et al. [16] in the presence of butylated hydroxytoluene as antioxidant. Tissue dissociation was achieved by homogenization in ice-cold chloroformmethanol $(2: 1, \mathrm{v} / \mathrm{v})$ containing $0.01 \%$ BHT using an Ultra Turrax model Type TP-18-1.

The lipid extract was quantified gravimetrically and kept in stoppered tubes under nitrogen atmosphere at $-30^{\circ} \mathrm{C}$ until assayed. Lipid composition was determined by means of the latroscan TLC/FID technique [17]. The latroscan MK-5 was used in combination with Chromarods $\mathrm{S}$, which have a precoated active silica thin layer. Samples of total lipids $(3 \mu \mathrm{l})$ were spotted onto each rod, using a 10- $\mu$ l Hamilton syringe. To separate total lipids, rods were developed in hexane/diethyl ether/ formic acid $(90: 10: 2, \mathrm{v} / \mathrm{v} / \mathrm{v})$. Rods were scanned under the following conditions: hydrogen flow, $150 \mathrm{ml} / \mathrm{min}$; air flow, $1750 \mathrm{ml} / \mathrm{min}$; scanning speed, $47 \mathrm{~mm} / \mathrm{s}$; chart speed, $42 \mathrm{~mm} / \mathrm{min}$. An latrocorder TC-11 integrator was used for recording and area integration.

\section{Fatty Acid Analysis}

Fatty acid weight percentages were determined by gas chromatography (GC), as previously described [18]. The samples were saponified by heating for $25 \mathrm{~min}$ with $5 \mathrm{ml}$ of $0.2 \mathrm{M}$ sodium methylate and heated again at $80^{\circ} \mathrm{C}$ for 25 min with $6 \%$ (w/v) $\mathrm{H}_{2} \mathrm{SO}_{4}$ in anhydrous methanol. The fatty acid methyl esters thus formed were eluted with hexane and analyzed in a Hewlett-Packard 5890 series II gas chromatograph equipped with flame ionization detector and using an Omegawak 320 fused silica capillary column $(30 \mathrm{~m} \times 0.32 \mathrm{~mm}$ i.d., $0.25 \mathrm{~mm}$ film $)$. The initial column temperature was $200^{\circ} \mathrm{C}$, which was held for $10 \mathrm{~min}$, then programmed from 200 $230^{\circ} \mathrm{C}$ at $2^{\circ} \mathrm{C} / \mathrm{min}$.

\section{Non-Fatty Acid Components}

For the extraction of the unsaponifiable matter, $20 \mathrm{~g}$ of oils was saponified for $30 \mathrm{~min}$ with $75 \mathrm{ml}$ of $10 \%$ ethanolic potassium hydroxide. The solution was transferred to a $5000 \mathrm{ml}$ decanting funnel, $100 \mathrm{ml}$ distilled water was added and the mixture was extracted with $100 \mathrm{ml}$ portions of hexane. The hexane solution was evaported to dryness in a rotatory evaporator at $30^{\circ} \mathrm{C}$ under reduced pressure. The sterol fraction was analyzed by capillary gas-liquid chromatography [19]. Tocopherols were analyzed by high-performance liquid chromatography [20]. For the assay of squalene, the hydrocarbon fraction was separated from the oil by column chromatography on silica gel and analyzed by capillary gas-liquid chromatography [21]. The composition of the polyphenol fraction was determined by capillary gasliquid chromatogaphy [22].

\section{Enzyme Activities}

Catalase activity was assayed according to the method of Beers and Sizer [23]. The final concentrations in the cuvettes were $500 \mathrm{mM}$ potassium phosphate $(\mathrm{pH} 7)$, 
$100 \mathrm{mM} \mathrm{H} \mathrm{H}_{2} \mathrm{O}_{2}$ and tissue sample $(0.05-0.1 \mathrm{mg})$. The decrease in the absorbance at $240 \mathrm{~nm}$ after the addition of the substrate was followed spectrophotometrically. Glutathione peroxidase activity was assayed with a coupled enzyme system in which GSSG reduction was coupled to NADPH oxidation by glutathione reductase [24]. The assay mixture contained $100 \mathrm{mM}$ potassium phosphate ( $\mathrm{pH} 7.5), 5 \mathrm{mM}$ EDTA, $2 \mathrm{mM} \mathrm{NaN}, 1 \mathrm{mM} \mathrm{GSH}, 0.2 \mathrm{mM}$ NADPH, $1 \mathrm{U}$ glutathione reductase and tissue sample $(0.05-0.2 \mathrm{mg})$. After $5 \mathrm{~min}$ pre-incubation $\left(20-25^{\circ} \mathrm{C}\right)$, the reaction was initiated by the addition of $0.05 \mathrm{ml} 5 \mathrm{mM} \mathrm{H}_{2} \mathrm{O}_{2}$ (final volume $1.0 \mathrm{ml}$ ). The decrease in the absorbance at $365 \mathrm{~nm}$ was followed spectrophotometrically. Superoxide dismutase activity was measured using the xanthine-oxidase-cytochrome $c$ method as described by McCord and Fridovich [25]. The final concentrations in the cuvettes were $50 \mathrm{mM}$ potassium phosphate ( $\mathrm{pH} 7.8), 0.1 \mathrm{mM}$ EDTA, $10 \mathrm{mM}$ cytochrome $c$, $50 \mathrm{mM}$ xanthine, $50 \mathrm{mM}$ or $2 \mathrm{mM}$ cyanide, $1 \mathrm{U}$ catalase, and tissue sample $(0.05-1 \mathrm{mg})$. The reaction was initiated by the addition of $1 \mathrm{U}$ xanthine-oxidase. The inhibition of xanthine-oxidase was followed spectrophotometrically at $550 \mathrm{~nm}$. One unit of SOD activity is defined as the amount of enzyme required to inhibit the rate of cytochrome $c$ reduction by $50 \%$. NADPH-cytochrome $c$ reductase activity was measured as described by Vermilion and Coon [26]. The $1.0 \mathrm{ml}$ assay mixture contained the following components: $300 \mathrm{mM}$ phosphate buffer $(\mathrm{pH} 7.7), 0.04 \mathrm{mM}$ cytochrome $c, 0.1 \mathrm{mM}$ EDTA, $0.2 \mathrm{mM}$ NADPH and tissue $(0.05-0.2 \mathrm{mg})$. The reaction was initiated by the addition of the NADPH, and the reduction of cytochrome $c$ was followed spectrophotometrically at $550 \mathrm{~nm}$.

\section{Statistical Methods}

All spectrophotometric measurements were carried out in a Shimadzu 160 A ultraviolet spectrophotometer with $1.0 \mathrm{ml}$ quartz cuvettes with a light path of $1.0 \mathrm{~cm}$. All enzyme assays were performed at $25^{\circ} \mathrm{C}$. Specific activities were expressed as $\mathrm{nmol} / \mathrm{min}$ per $\mathrm{mg}$ protein. Protein concentrations were determined by the method of Lowry et al. [27].

All results were subjected to one-way analysis of variance (ANOVA), and represent means \pm SEM of 10 animals per group. Differences in mean values between groups were assessed by the two-tailed Student's $t$-test and were considered statistically different at $p<0.05$.

\section{RESULTS}

In the present study, rats in the four experimental groups consumed similar amounts of food (Table 4). After 12 weeks of dietary intervention, animals fed on diets containing OO or HOSO had similar body weights, but these were higher than those of animals fed on the control or FO diets were. Animals fed on the diet containing FO had significantly lower body and liver weights when compared with the other groups; however, the liver/body weight ratio was similar in all the groups. Liver lipid content was higher in animals fed on the OO and HOSO diets than in those fed on the control or FO diets. 
Table 4. Effect of Dietary Fats on Body Weight, Food Intake, Liver Weights, and Liver Lipid Content

\begin{tabular}{lcccc}
\hline & Control & OO & HOSO & FO \\
\hline Food intake (g/day) & $19.8 \pm 1.1$ & $22.0 \pm 1.7$ & $20.8 \pm 2.2$ & $18.1 \pm 2.8$ \\
Body weight (g) & & & & \\
$\quad$ at entry & $67.6 \pm 6.3$ & $69.3 \pm 7.2$ & $68.3 \pm 6.1$ & $70.6 \pm 7.4$ \\
$\quad$ at study & $214.4 \pm 8.6$ & $246.5 \pm 6.1^{a}$ & $237.1 \pm 7.9^{a}$ & $165.4 \pm 3.6^{a, b}$ \\
Liver weight (g) & $7.8 \pm 0.9$ & $9.1 \pm 1.1$ & $8.1 \pm 0.9$ & $6.1 \pm 0.2^{a, b}$ \\
Liver/body weight (\%) & $3.6 \pm 0.2$ & $3.7 \pm 0.3$ & $3.4 \pm 0.2$ & $3.7 \pm 0.4$ \\
Liver lipid content (\%) & $2.0 \pm 0.4$ & $4.6 \pm 0.5^{a}$ & $4.3 \pm 0.4^{a}$ & $3.1 \pm 0.3^{a, b}$ \\
\hline
\end{tabular}

Values represent means \pm SEM of 10 animals per group. Statistical significance: ${ }^{a} p<0.05$ vs. control; ${ }^{b} p<0.05$ vs. OO and HOSO. Abbreviations: OO, olive oil $(10 \% \mathrm{w} / \mathrm{w})$; HOSO, high-oleic-acid sunflower oil $(10 \% \mathrm{w} / \mathrm{w})$; FO, fish oil $(10 \% \mathrm{w} / \mathrm{w})$.

Table 5. Effect of Dietary Fat Treatment on Plasma Lipid Content

\begin{tabular}{lcccc}
\hline Plasmid lipid & Control & OO & HOSO & FO \\
\hline Triacylglycerols (mmol/1) & $0.64 \pm 0.14$ & $0.91 \pm 0.12^{a}$ & $1.07 \pm 0.18^{a}$ & $0.26 \pm 0.13^{a, b}$ \\
Cholesterol (mmol/1) & $1.19 \pm 0.25$ & $2.65 \pm 0.43^{a}$ & $2.26 \pm 0.32^{a}$ & $1.45 \pm 0.22$ \\
Phospholipids (mmol/1) & $0.99 \pm 0.04$ & $1.64 \pm 0.16^{a}$ & $1.59 \pm 0.17^{a}$ & $1.14 \pm 0.12$ \\
\hline
\end{tabular}

Values represent means \pm SEM of 10 animals per group. Statistical significance: ${ }^{a} p<0.05$ vs. control; ${ }^{b} p<0.05$ vs. OO and HOSO. Abbreviations: OO, olive oil $(10 \% \mathrm{w} / \mathrm{w})$; HOSO, high-oleic-acid sunflower oil $(10 \% \mathrm{w} / \mathrm{w})$; FO, fish oil $(10 \% \mathrm{w} / \mathrm{w})$.

Table 5 shows the effect of dietary fat treatment on plasma lipid content. When compared with the control diet, the HOSO and OO diets led to significant increases and the FO led to a significant decrease in plasma triacylglycerol level. Consumption of the FO diet resulted in a decrease in the total cholesterol and phospholipid concentrations in plasma in comparison with the high-oleic-acid diets. The HOSO and OO groups did not differ in plasma lipid concentrations, but these were higher than those in the control group.

Total triacylglycerol concentrations in liver are shown in Table 6. The OO-fed group showed the highest values and the FO-fed group the lowest. Total hepatic cholesterol and phospholipids were lowest in the animals fed on the control diet. The animals fed on the oil-enriched diets showed similar hepatic cholesterol and phospholipid contents.

Table 6. Effect of Dietary Fat Treatment on Liver Lipid Content

\begin{tabular}{lrrrr}
\hline Liver lipid & Control & \multicolumn{1}{c}{ OO } & \multicolumn{1}{c}{ HOSO } & \multicolumn{1}{c}{ FO } \\
\hline Triacylglycerols (mg/g) & $5.1 \pm 1.1$ & $20.8 \pm 2.8^{a}$ & $17.3 \pm 2.2^{a}$ & $2.7 \pm 0.6^{a, b}$ \\
Cholesterol (mg/g) & $0.8 \pm 0.1$ & $2.6 \pm 1.2^{a}$ & $2.2 \pm 0.3^{a}$ & $2.8 \pm 0.4^{a}$ \\
Phospholipids (mg/g) & $14.3 \pm 2.2$ & $22.6 \pm 1.7^{a}$ & $22.5 \pm 1.8^{a}$ & $25.5 \pm 2.3^{a}$ \\
\hline
\end{tabular}

Values represent means \pm SEM of 10 animals per group. Statistical significance: ${ }^{a} p<0.05$ vs. control; ${ }^{b} p<0.05$ vs. OO and HOSO. Abbreviations: OO, olive oil $(10 \%$ $\mathrm{w} / \mathrm{w})$; HOSO, high-oleic-acid sunflower oil $(10 \% \mathrm{w} / \mathrm{w})$; FO, fish oil $(10 \% \mathrm{w} / \mathrm{w})$. 
Table 7. Effect of Dietary Fats on the Fatty Acid Composition ( $\%$ w/w) of Rat Liver

\begin{tabular}{|c|c|c|c|c|}
\hline Fatty acids & Control & $\mathrm{OO}$ & HOSO & FO \\
\hline $14: 0$ & $0.5 \pm 0.1$ & $0.3 \pm 0.1$ & $0.4 \pm 0.1$ & $0.3 \pm 0.1$ \\
\hline $16: 0$ & $22.2 \pm 2.2$ & $15.5 \pm 0.3^{a}$ & $16.7 \pm 0.5^{a}$ & $20.9 \pm 1.3$ \\
\hline $16: 1(n-7)$ & $3.6 \pm 1.0$ & $0.7 \pm 0.2^{a}$ & $1.3 \pm 0.3^{a}$ & $0.9 \pm 0.1^{a}$ \\
\hline $18: 0$ & $18.1 \pm 1.4$ & $13.5 \pm 1.5^{a}$ & $13.5 \pm 1.2^{a}$ & $18.4 \pm 1.4$ \\
\hline $18: 1(n-9)$ & $15.4 \pm 3.5$ & $33.5 \pm 2.8^{a}$ & $28.5 \pm 2.5^{a}$ & $9.0 \pm 0.2^{a, b}$ \\
\hline $18: 1(n-7)$ & $3.6 \pm 0.9$ & $2.5 \pm 0.2$ & $2.5 \pm 0.1$ & $1.9 \pm 0.5$ \\
\hline $18: 2(n-6)$ & $14.2 \pm 2.2$ & $13.5 \pm 0.5$ & $14.6 \pm 1.7$ & $13.0 \pm 1.7$ \\
\hline $18: 3(n-3)$ & $0.2 \pm 0.1$ & $0.2 \pm 0.0$ & $0.2 \pm 0.0$ & $0.2 \pm 0.0$ \\
\hline $20: 0$ & $0.4 \pm 0.1$ & $0.4 \pm 0.1$ & $0.3 \pm 0.1$ & $0.2 \pm 0.1$ \\
\hline $20: 1(n-9)$ & $0.1 \pm 0.0$ & $0.4 \pm 0.1^{a}$ & $0.3 \pm 0.1^{a}$ & $0.1 \pm 0.0$ \\
\hline $20: 4(n-6)$ & $16.2 \pm 3.9$ & $14.8 \pm 1.2$ & $16.2 \pm 1.3$ & $11.3 \pm 0.9^{a, b}$ \\
\hline $20: 5(n-3)$ & $0.1 \pm 0.0$ & $0.2 \pm 0.0$ & $0.1 \pm 0.0$ & $2.1 \pm 0.1^{a, b}$ \\
\hline $22: 0$ & $0.4 \pm 0.1$ & $0.3 \pm 0.1$ & $0.3 \pm 0.1$ & $0.8 \pm 0.1^{a, b}$ \\
\hline $22: 4(n-6)$ & $0.4 \pm 0.1$ & $0.5 \pm 0.0$ & $0.4 \pm 0.1$ & $0.5 \pm 0.1$ \\
\hline $22: 5(n-6)$ & $0.5 \pm 0.3$ & $0.2 \pm 0.0$ & $0.3 \pm 0.1$ & $0.3 \pm 0.1$ \\
\hline $22: 5(n-3)$ & $0.5 \pm 0.2$ & $0.8 \pm 0.1$ & $0.6 \pm 0.1$ & $5.5 \pm 0.4^{a, b}$ \\
\hline $22: 6(n-3)$ & $4.5 \pm 0.8$ & $3.6 \pm 0.3$ & $3.8 \pm 0.4$ & $14.6 \pm 1.5^{a, b}$ \\
\hline SFA & $41.6 \pm 2.4$ & $30.0 \pm 2.0^{a}$ & $31.2 \pm 1.9^{a}$ & $40.6 \pm 1.8$ \\
\hline MUFA & $22.7 \pm 0.7$ & $37.1 \pm 2.4^{a}$ & $32.6 \pm 1.4^{a}$ & $11.9 \pm 0.6^{a, b}$ \\
\hline PUFA & $36.6 \pm 1.6$ & $33.8 \pm 2.5^{a}$ & $36.2 \pm 2.3$ & $47.5 \pm 1.7^{a, b}$ \\
\hline Total $(n-6)$ & $31.1 \pm 1.8$ & $29.0 \pm 1.4$ & $31.5 \pm 1.7$ & $25.1 \pm 1.9^{a, b}$ \\
\hline Total $(n-3)$ & $5.3 \pm 0.3$ & $4.8 \pm 0.6$ & $4.7 \pm 0.4$ & $22.4 \pm 2.5^{a, b}$ \\
\hline$(n-6) /(n-3)$ & $5.9 \pm 1.7$ & $6.0 \pm 1.3$ & $6.7 \pm 1.2$ & $1.1 \pm 0.4^{a, b}$ \\
\hline MUFA/SFA & $0.5 \pm 0.2$ & $1.2 \pm 0.3^{a}$ & $1.0 \pm 0.2^{a}$ & $0.3 \pm 0.1$ \\
\hline $20: 4 / 18: 2$ & $1.1 \pm 0.3$ & $1.1 \pm 0.4$ & $1.1 \pm 0.2$ & $0.9 \pm 0.1$ \\
\hline
\end{tabular}

Values represent means \pm SEM of 10 animals per group. Statistical significance: ${ }^{a} p<0.05$ vs. control; ${ }^{b} p<0.05$ vs. OO and HOSO. Abbreviations: OO, olive oil $(10 \% \mathrm{ww} / \mathrm{w})$; HOSO, high-oleic-acid sunflower oil $(10 \% \mathrm{w} / \mathrm{w})$; FO, fish oil $(10 \% \mathrm{w} / \mathrm{w})$; SFA, saturated fatty acid; MUFA, monounsaturated fatty acid; PUFA, polyunsaturated fatty acid.

Table 7 shows the fatty acid weight percentages (WP) of liver lipids in rats fed on the different diets. The highest proportions of the two major saturated fatty acids, palmitic (16:0) and stearic (18:0) acids, were found in rats fed on the FO and control diets as compared with the high-oleic-acid oil groups. In consequence, the levels of total saturated fatty acids in liver were higher in the control and the FOfed groups in comparison with the animals fed on the diets enriched in oleic acid. The WP in 18:1 $(n-9)$ was similar in the OO- and HOSO-fed groups and higher in the control- or FO-fed animals. The FO group showed higher WP of long-chain PUFA of the $(n-3)$ series $(20: 5,22: 5$, and $22: 6)$ than the control, OO, or HOSO oils. The relation $(n-6) /(n-3)$ was markedly lower in the FO group.

The animals fed on the FO diet expressed higher CAT activity in the liver $(4.40 \pm 0.03 \mathrm{U} / \mathrm{mg}$ protein) when compared with the other groups (Fig. 1A). The catalase activity was similar in the OO and HOSO groups (approximately $2.80 \mathrm{U} /$ $\mathrm{mg}$ protein) and was lower than the control group. The glutathione peroxidase activity in animals fed on the control, OO, and HOSO diets was similar. Feeding on the FO diet increased the activity to $0.60 \pm 0.05 \mathrm{U} / \mathrm{mg}$ protein (Fig. 1B). 


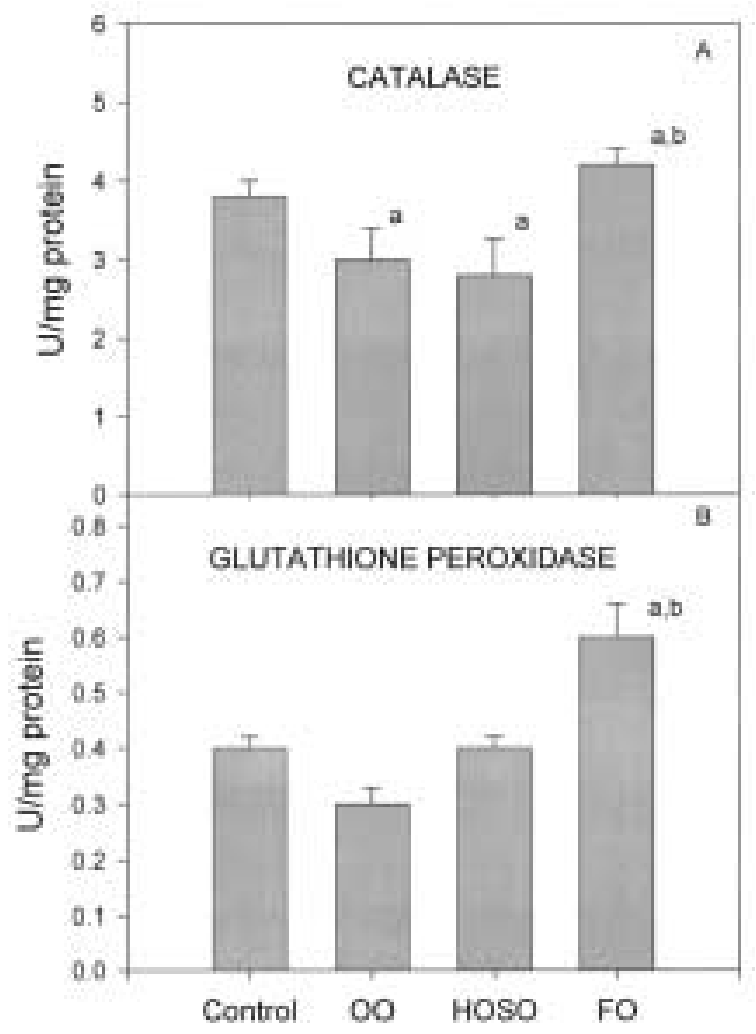

Fig. 1. Effect of dietary fat on the specific activity of catalase (A) and glutathione peroxidase (B) from rat liver. The results are expressed as means \pm SEM of 10 animals. Statistical significance: ${ }^{a} p<0.05$ vs. control; ${ }^{b} p<0.05$ vs. OO and HOSO. Abbreviations: OO, olive oil $(10 \% \mathrm{w} / \mathrm{w})$; HOSO, high-oleic-acid sunflower oil $(10 \% \mathrm{w} / \mathrm{w})$; FO, fish oil $(10 \% \mathrm{w} / \mathrm{w})$.

The $\mathrm{Cu} / \mathrm{Zn}$ SOD activity had the highest values in the FO-fed group $(3.8 \pm 0.7$ $\mathrm{U} / \mathrm{mg}$ protein) and was significantly higher than the other groups. The oleic acidenriched oils had no effect on $\mathrm{Cu} / \mathrm{Zn}$-SOD activity as compared with the control diet (Fig. 2A). The activity of NADPH cytochrome $c$ reductase was similar in liver of rats fed on the oil-enriched diets, which was higher than the control animals (Fig. 2B).

\section{DISCUSSION}

Increasing evidence suggests that essential hypertension is associated with elevated oxygen free radical production and decreased antioxidant capacity [1-3]. As diet can affect the endogenous free radical production and modulates the antioxidant status $[11,12]$, the present study was designed to compare the effect of different 


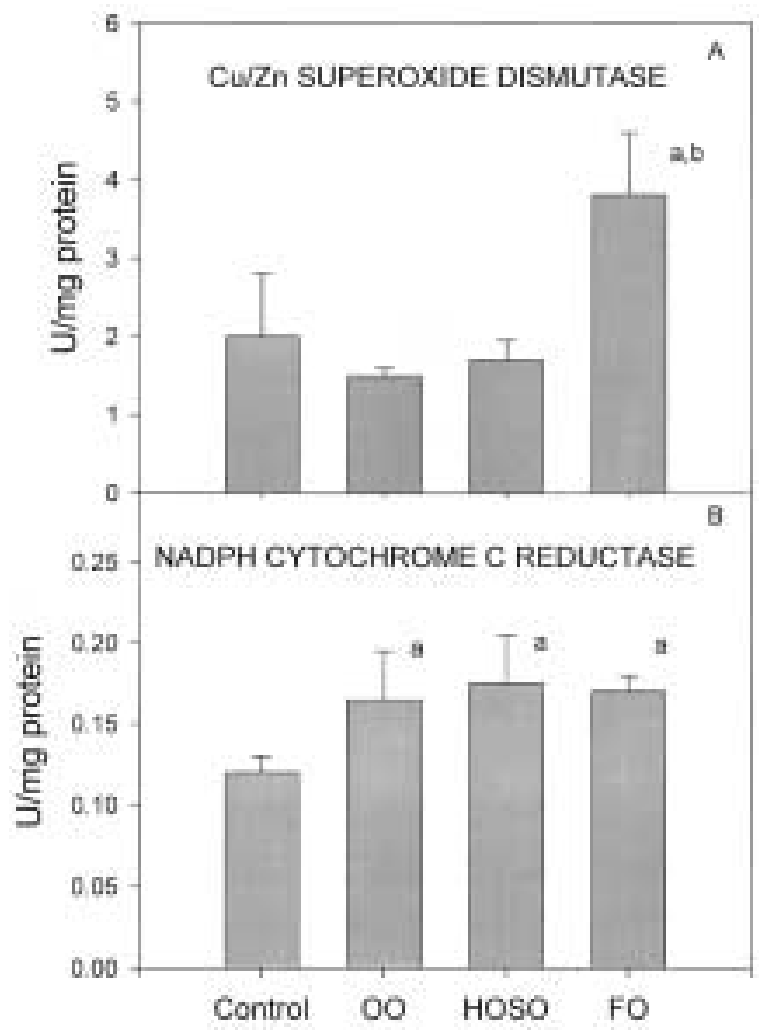

Fig. 2. Effect of dietary fat on the specific activity of $\mathrm{Cu} / \mathrm{Zn}$ superoxide dismutase (A) and NADPH cytochrome $c$ reductase (B) from rat liver. The results are expressed as means \pm SEM of 10 animals. Statistical significance: ${ }^{a} p<0.05$ vs. control; ${ }^{b} p<0.05$ vs. OO and HOSO. Abbreviations: OO, olive oil $(10 \%$ $\mathrm{w} / \mathrm{w})$; HOSO, high-oleic-acid sunflower oil $(10 \% \mathrm{w} / \mathrm{w}) ; \mathrm{FO}$, fish oil $(10 \% \mathrm{w} / \mathrm{w})$.

dietary fats on liver antioxidant activities in spontaneously hypertensive rats (SHR). The plasma and liver lipid composition was also studied. The oils tested are olive oil and high-oleic-acid sunflower oil, with the same high content of oleic acid but different contents of natural antioxidants, and fish oil, a PUFA oil very susceptible to peroxidation and production of free radicals.

Liver lipid triacylglycerol (TAG) levels were lowest in FO-fed rats (Table 6). This may have been due to inhibition of hepatic TAG synthesis [28] and stimulation of hepatic peroxisomal $\beta$-oxidation [29] produced by the FO diet. Decreases in lipoprotein lipase and triacylglycerol lipase activities in the liver after FO consumption have also been described [30], and this may be an adaptive response to the low concentrations of substrates (triacylglycerols) for these enzymes. The low levels of hepatic TAG after FO intake is also observed in normotensive rats [11] and may be related to the reduced levels of plasma TAG found in our study (Table 5) and also 
described in normotensive rats [11] and in man [29]. We have detected similar hepatic TAG content in animals fed on the two MUFA-enriched diets. Despite a similar TAG content, the molecular composition of TAG of the liver differs greatly for SHR fed on OO or HOSO [31]. As VLDL triacylglycerol depends on the composition of liver TAG, there may be an influence on membrane fatty acid composition and fluidity, as well as eicosanoid output, which has a bearing on hypertension pathology.

Cholesterol levels in liver were increased in animals fed on the lipid-supplemented diets compared with the control group, without differences between those diets (Table 6). In plasma, cholesterol content was higher in the high-oleic-acid diets compared with control or FO diets. FO consumption reduces cholesterol levels in blood, and is more hypocholesterolemic than OO [32]. MUFA, especially in the form of OO, also lowers cholesterol in blood [33]. It was suggested that the nonglyceride fraction of $\mathrm{OO}$ contributes to the hypocholesterolemic effect [34]. Neither squalene nor tocopherol was responsible for the cholesterol lowering action and phytosterols were responsible of this effect [35]. Although HOSO has higher sterols than OO [9], we have found no difference in the liver cholesterol content in the animals fed HOSO or OO.

Analysis of the fatty acid content of rat liver homogenates showed a significant increase of 18:1 in liver lipids obtained from OO- and HOSO-fed rats. We also found lower saturated fatty acids in both groups. The increase in oleic acid content was probably related to the higher content of oleic acid in the diet of these animals. When endothelial cell cultures are directly supplemented with oleic acid, an increase in its content is found, accompanied by a decrease in the saturated acid content [36]. With respect to the FO diet, we found a marked increase in weight percentage (WP) of total $((n-3)$ fatty acids (mainly 20:5 and 22:6), and a concomitant decrease in $(n-6)$ fatty acids in the liver. As a consequence, a significant reduction in the ratio $(n-6) /(n-3)$ was found in these animals. When we compare arachidonic acid content between SHR and normotensive rats [11] we observe that arachidonic acid content is lower in the SHR in all the diets studied. This fact may be due to lower desaturase activity in SHR than in Wistar normotensive rats and decreased bioconversion of linoleic to arachidonic acid in liver of SHR [37, 38].

The antioxidant defence system is well characterized in the liver, which includes $\mathrm{Cu} / \mathrm{Zn}$ superoxide dismutase, catalase and glutathione peroxidase. We have reported that the dietary fats modulate these enzyme activities in normotensive rats [11]. In the present work, we have found that, in SHR, these activities also depend on the kind of fat in the diet. SHR fed on the FO diet had higher activities of GSH-Px, $\mathrm{CAT}$, and $\mathrm{Cu} / \mathrm{Zn}$ SOD compared with those fed on the control diet and the oleic acid-enriched diets. The high levels of PUFA $(n-3)$ in the liver of the rats fed on the FO might render this organ more susceptible to lipid peroxidation and the activity of antioxidant enzymes might be induced. An induction in the expression of antioxidant enzymes has been reported in circumstances where an increase in free radicals is produced, such as ageing [39] or several hepatic pathologies [40]. Possibly, free radicals regulate the expression of these antioxidant enzymes genes, in the same way that they regulate the transcription of other many genes [41]. 
In normotensive rats, a greater activity of antioxidant enzymes in animals fed on the FO in comparison with animals fed on the other diets has been also described by us [11] and other authors [29, 42, 43]. However, other studies have reported that, after FO intake, the activities of some antioxidant enzymes remain unchanged [44] or even decreased [45]. In hypertensive rats, Yuang et al. [46] have studied the effects of varying dietary fat saturation or polyunsaturation on tissue antioxidant status. These authors have found that CAT activity was not affected by the diet, SOD activity was lower and GSH-Px higher in rats fed $(n-3)$ diets compared with those fed on the diets containing saturated fat.

The greater activity of antioxidant enzymes may contribute to the hypothesis that consumption of FO extends life span [47]. Antioxidants have been closely linked with the preservation of health and longevity [48]. Another possibility to the relationship between FO intake and longevity is the slow growth rate associated to a diet enriched in FO. We have found that animals fed on the diet containing FO had significantly lower body weight when compared with the other groups. This fact has been also described by others [46].

Fatty acids are known to influence blood pressure and membrane composition. Diets enriched in polyunsaturated fatty acids (PUFA) of the $n-3$ series have been observed to reduce blood pressure [6] although the mechanism(s) of action are not fully understood. Recently it has been proposed that these fatty acids could be of benefit in essential hypertension because $(n-3)$ fatty acids can inhibit the synthesis and release of pro-inflammatory cytokines [49]. On the other hand, increasing evidence suggests that hypertension may be associated with enhanced decomposition of nitric oxide by superoxide anion [50]. So, the increase in antioxidant capacity observed in the present study after FO consumption may be also another mechanism to improve the hypertension status observed after the intake of PUFA of the $(n-3)$ series.

Like FO, OO also reduces blood pressure. In contrast, the new high-oleic-acid variety of sunflower oil (HOSO), which has a similar fatty acid composition to OO (Table 3), but different antioxidant content, does not provide favorable effects on blood pressure [10]. In the present study we have tested the effect of these two MUFA oils on the antioxidant enzyme activities in liver, and we have found no differences between them. The non-glyceride fractions of these oils are different; polyphenols, which have free radical-scavenging properties, are only present in OO, and tocopherols, which also have an antioxidant effect, are higher in OO. These differences in the natural antioxidant content in the two oils seems not to affect the activity of the hepatic antioxidant enzymes studied in SHR. So the differences found in the hypotensive effect between OO and HOSO [10] cannot be attributed to a differential induction of antioxidant systems in the liver. We have found comparable results in normotensive rats [11].

In comparison with the antioxidant enzyme activities in normotensive Wistar rats [11], we observed that CAT and GSH-PX were lower in SHR in all the diets. $\mathrm{Cu} / \mathrm{Zn}$ SOD activity was lower in the SHR in the rats fed on the high-oleic-acid diets and similar in both strains in the animals fed on the control or FO diets. This data supports the notion that there is a decreased antioxidant capacity in hypertension [1]. 
NADPH cytochrome $c$ reductase participates in the detoxification of drugs and xenobiotics. Similar activities of NADPH cytochrome $c$ reductase were observed in rats fed on the OO, HOSO, and FO diets in the present study, but each oil diet supported higher activity than the control diet. NADPH cytocrome $c$ reductase activity was higher in the SHR in all the groups compared with normotensive rats [11]. This may suggest a greater oxidative drug metabolism in hypertensive animals; other enzymes involved in xenobiotic transformation are also increased in SHR compared with normotensive rats [51].

In summary, it appears that changes in the liver fatty acid composition, due mainly to $n-3$ lipids, may increase the activity of some antioxidant enzymes and suggest that FO in the diet may increase the endogenous antioxidant status and reduce the risk of free radical damage in the hypertension. On the other hand, the two MUFA oils studied (OO and HOSO), in spite of their different contents of natural antioxidants, have similar effects on the antioxidant enzyme activities studied.

\section{ACKNOWLEDGMENTS}

The present study was supported by a grant (AL199-0863) from the Comisión Interministerial de Ciencia y Tecnología, Spain. We wish to thank Koipe S.A. Industria and Aceites Toledo, Industria, for kindly providing the oils used in this study. We are grateful to Fernanda León and Alonso Pérez-Espinosa for expert technical assistance.

\section{REFERENCES}

1. Russo, C. et al. (1998) Antioxidant status and lipid peroxidation in patients with essential hypertension. J. Hypertens. 16:1267-1271.

2. Galley, H. F., Thornton, J., Howdle, P. D., Walker, B. E., and Webster, N. R. (1997) Combination oral antioxidant supplementation reduces blood pressure. Cli. Sci. 92:361-365.

3. Akpaffionng, M. J. and Taylor, A. A. (1998) Antihypertensive and vasodilator actions of antioxidants in spontaneously hypertensive rats. Am. J. Hyperten. 11:1450-1460.

4. Carlos, D. M. et al. (1998) Nicardipine normalizes elevated levels of antioxidant activity in response to xantine oxidase-induced oxidative stress in hypertensive rat heart. Free Rad. Res. 29:143-150.

5. Tang, Z., Shou, I., Wang, L. N., Fukui M., and Tomino, Y. (1997) Effects of antihypertensive drugs or glycemic control on antioxidant enzyme activities in spontaneously hypertensive rats with diabetes. Nephron 76:323-330.

6. Engler, M. B., May, Y. H., and Engler, M. M. (1999) Calcium-mediated mechanisms of eicosapentaenoic acid-induced relaxation in hypertensive rat aorta. Am. J. Hypertens. 12:1225-1235.

7. Watanabe, Y., Huang, Y., Simmons, V. A., and Horrobin, D. F. (1989) The effect of dietary $n-6$ and $n-3$ polyunsaturated fatty acids on blood pressure and tissue fatty acid composition in spontaneously hypertensive rats. Lipids 24:638-644.

8. Papadopoulos, G. and Boskou, D. (1991) Antioxidant effect of natural phenols on olive. J. Am. Oil Chem. Soc. 68:669-671.

9. Pérez-Jiménez. F. et al. (1995) Lipoprotein concentrations in normolipidemic males consuming oleic acid-rich diets from two different sources: olive oil and oleic acid-rich sunflower oil. Am. J. Cli. Nutr. 62:769-777.

10. Ruiz-Gutiérrez, V., Muriana, F. J. G., Guerrero, A., Cert, A. M., and Villar, J. (1996) Plasma lipids, erythrocyte membrane lipids and blood pressure of hypertensive women after ingestion of dietary oleic acid from two different sources. J. Hypertens. 14:1483-1490. 
11. Ruiz-Gutiérrez, V., Pérez Espinosa, A., Vazquez, C. M., and Santa María, C. (1999) Effects of dietary fats (fish, olive, and high-oleic sunflower oils) on lipid composition and antioxidant enzymes in rat liver. Brit. J. Nutr. 82:233-241.

12. Huang, C. Y., Chen, L. H., Osio, Y., and Coen, D. A. (1994) Effects of diet composition on liver antioxidant defence and detoxification enzymes in mice with murine AIDS. Nut. Res. 14:1841-1851.

13. Nelson, G. J. (1972) Quantitative analysis of bloods lipids. In: Blood Lipids and Lipoproteins: Quantitation, Composition, and Metabolism (G. J. Nelson, ed.), Wiley-Interscience, New York, pp. 171-198.

14. Bucolo, G. and David, H. (1973). Quantitative determination of plasma triglycerides by use of enzymes. Clin. Chem. 19:476-482.

15. Allain, C. C., Poon, L. S., Chang, C. S. G., Richmond, W., and Fu P. C. (1974) Enzymatic determination of total plasma cholesterol. Clin. Chem. 20:47-475.

16. Folch, J., Lees, M., and Sloan-Stanley, G. H. (1957) A simple method for the isolation and purification of total lipids from the animal tissues. J. Biol. Chem. 26:497-509.

17. De Schrijver, R. and Vermeulen, D. (1991) Separation and quantification of phospholipids in animal tissues by latroscan TLC/FID. Lipids 26:74-75.

18. Molina, M. T., Vázquez, C. M., and Ruiz-Gutiérrez, V. (1989) Changes in both acyl-CoA:cholesterol acyltransferase activity and microsomal lipid composition in rat liver induced by distal small-bowel resection. Biochem. J. 260:115-119.

19. Garcia Regueiro, J. A., Gilbert, J., and Diaz, I. (1994) Determination of neutral lipids from subcutaneous fat of cured ham by capillary gas chromatography and liquid chromatography. J. Chromatogr. A. 667:225-233.

20. Kramer, J. K., Blais, L., Fouchard, R. C., Melnyk, R. A., and Kallery, K. M. (1997) A rapid method for the determination of vitamin $\mathrm{E}$ forms in tissues and diet by high-performance liquid chromatography using a normal-phase diol column. Lipids 32:323-330.

21. Sulpice, J. C. and Ferezou, J. (1984) Squalene isolation by HPLC and quantitative comparison by HPLC and GLC. Lipids 19:631-635.

22. Arce, L., Rios, A., and Valcarcel, M. (1998) Determination of anti-carcinogenic polyphenols present in green tea using capillary electrophoresis coupled to a flow injection system. J. Chromatogr. A. 827:113-120.

23. Beers, R. F. and Sizer, I. W. (1952) A spectrophotometric method for measuring the breakdown of hydrogen peroxide by catalase. J. Biol. Chem. 195:133-140.

24. Lawrence, A. and Burk, R. F. (1976) Glutathione peroxidase activity in selenium deficient rat liver. Biochem. Biophys. Res. Commun. 71:952-958.

25. McCord, J. M. and Fridovich, I. (1969) Superoxide Dismutase. An enzymatic function for erythrocuprein (hemocuprein). J. Biol. Chem. 244:6049-6055.

26. Vermilion, J. L. and Coon, M. J. (1978) Purified liver microsomal NADPH-cytochrome P-450 reductase. Spectral characterization of oxidation-reduction states. J. Biol. Chem. 253:2694-2704.

27. Lowry, O. H., Rosebrough, N. J., Farr, A. L., and Randall, R. L. (1951) Protein measurement with the folin phenol reagent. J. Biol. Chem. 193:265-275.

28. Wong, S. H., Nestel, P. J., Trimble, R. P., Store, G. B., Illman, R. J., and Topping, D. L. (1984) The adaptive effects of dietary fish and safflower oil on lipid and lipoprotein metabolism in perfused rat liver. Biochim. Biophys. Acta 792:103-109.

29. Yamazaki, R. K., Shen, T., and Schade, G. B. (1987) A diet rich in $(n-3)$ fatty acids increases peroxisomal $\beta$-oxidation activity and lowers plasma triacylglycerols without inhibiting glutathionedependent detoxification activities in the rat liver. Biochim. Biophys. Acta 920:62-67.

30. Huff, M. W., Telford, D. E., Edmonds, B. W., McDonalds, C. G., and Evans, A. J. (1993) Lipoprotein lipases, lipoprotein density gradient profile and LDL receptor activity in miniature pigs fed fish oil and corn oil. Biochim. Biophys. Acta 1210:113-122.

31. Perona, J. S. and Ruiz-Gutiérrez,V. (2000) Effect of two high-oleic oils on the liver lipid composition of spontaneously hypertensive rats. Life Sciences 66:521-531.

32. Masi, I., Giani, E., Galli, C., Tremoli, E., and Sirtori, C. R. (1986) Diets rich in saturated, monounsaturated and polyunsaturated fatty acids differently affect plasma lipid, platelet, and arterial wall eicosanoids in rabbits. Ann. Nutr. Metab. 30:66-72. 
33. Mattson, F. H., and Grundy, S. M. (1985) Comparison of effects of dietary saturated, monounsaturated, and polyunsaturated fatty acids on plasma lipids and lipoproteins in man. J. Lipid Res. 26:194202.

34. Huang, Y. S., Redden, P., Lin, X., Smith, R., Mackinnon, S., and Horrobin, D. F. (1991) Effect of dietary olive oil non-glyceride fraction on plasma cholesterol level and liver phospholipid fatty acid composition. Nutrition Res. 11: 439-448.

35. Kiribuchi, M., Miura, K., Tokuda, S., and Kaneda, T. (1983) Hypocholesterolemic effect of triterpene alcohols with soysterol on plasma cholesterol in rats. J. Nutr. Sci. Vitaminol. 29:35-43.

36. Spector, A. A. and Yorek, M. A. (1985) Membrane lipid composition and cellular function. J. Lipid Res. 26:1015-1035.

37. Foucher, C., Narce, M., Nasr, L., Delachambre, M. C., and Poisson, J. P. (1997) Liver microsomal membrane fluidity and microsomal desaturase activities in adult spontaneously hypertensive rats. Hypertens. 15:863-869.

38. Narce, M. and Poisson, J. P. (1996) Polyunsaturated fatty acid biogenesis is impaired in spontaneously hypertensive rat in relation to the pathogenesis of hypertension. Arch. Mal. Coeur Vaiss 89:1025-1028.

39. De Haan, J. B., Newman, J. D., and Kola, I. (1992) Cu/Zn superoxide dismutase mRNA and enzyme activity, and susceptibility to lipid peroxidation, increases with ageing in murine brains. Brain Res. Mol. Brain Res. 13:179-187.

40. Larrea, E., Beloqui, O., Muñoz-Navas, M. A., Civeira, M. P., and Prieto, J. (1998) Superoxide dismutase in patients with chronic hapatitis C virus infection. Free Radic. Biol. Med. 24:1235-1241.

41. Roche, E. and Romero-Alvira, D. (1995) Role of oxidative stress in gene expression: myocardial and cerebral ischemia, cancer and other diseases. Med. Clin. 104:468-476.

42. Venkatraman, J. L., Angkeow, P., Satsangi, N., and Fernandes, G. (1998) Effects of dietary $n-6$ and $n-3$ lipids on antioxidants defence system in livers of exercised rats. J. Am. Coll. Nutr. 17:586-594.

43. Venkatraman, J. T., Chandrasekar, B., Kim, J. D., and Fernandes, G. (1994) Effects of $n-3$ and $n-6$ fatty acids on the activities and expression of hepatic antioxidant enzymes in autoimmune-prone NZBXNZW F 1 mice. Lipids 29:561-568.

44. Nalbone, G. et al. (1980) Effects of fish, oil, corn oil, and lard diets on lipid peroxidation status and glutathione peroxidase activities in rat heart. Lipids 24:179-186.

45. L'Abbe, M. R., Trick, K. D., and Beare-Rogers, J. L. (1991). Dietary $(n-3)$ fatty acids affect rat heart, liver, and aorta protective enzyme activities and lipid peroxidation. J. Nutr. 121:1331-1340.

46. Yuan, Y. V., Kitts, D. D., and Godin, D. V. (1998) Variations in dietary fat and cholesterol intakes modify antioxidant status of SHR and WKY rats. J. Nutr. 128:1620-1630.

47. Jeng, K. C. and Fernandes, G. (1991). Effect of fish oil diet on immune response and proteinuria in mice. Proc. Natl. Sci. Coun. Repub. China 15:105-110.

48. Rao, G., Xia, E., and Richardson, A. (1990) Effect of age on the expression of antioxidant enzymes in male Fischer F 344 rats. Mech. Ageing Dev. 53:49-60.

49. Das, U. N. (2000) Beneficial effect(s) of $n-3$ fatty acids in cardiovascular diseases: but, why and how? Prostaglandins Leukot. Esset. Fatty Acids 63:351-362.

50. Tschudi, M. R., Mesaros, S., Luscher, T. F., and Malinski, T. (1996) Direct in situ measurement of nitric oxide in mesenteric resistance arteries: increased decomposition by superoxide in hypertension. Hypertension 27:32-35.

51. Hynie, S., Kren, V., Mraz, M., and Farghali, H. (1998) Phase I and phase II xenobiotic biotransformation in different inbred strains of rats: study in immobilized perfused hepatocytes. Folia Biol. 44:127-132. 